\title{
Effects of nitrogen on the apoptosis of and changes in gene expression in human lymphoma U937 cells exposed to argon-based cold atmospheric pressure plasma
}

\author{
YOSHIAKI TABUCHI ${ }^{1}$, HIDEFUMI UCHIYAMA ${ }^{3}$, QING-LI ZHAO ${ }^{2}$, TATSUYA YUNOKI ${ }^{2}$, GABOR ANDOCS $^{3}$, \\ NOBUYUKI NOJIMA $^{3}$, KEIGO TAKEDA ${ }^{4}$, KENJI ISHIKAWA ${ }^{4}$, MASARU HORI ${ }^{4}$ and TAKASHI KONDO ${ }^{2}$ \\ ${ }^{1}$ Division of Molecular Genetics Research, Life Science Research Center, University of Toyama; \\ ${ }^{2}$ Department of Radiological Sciences, Graduate School of Medicine and Pharmaceutical Sciences, \\ University of Toyama, Toyama 930-0194; ${ }^{3}$ Tateyama Machine Co., Ltd., Toyama 930-1305; \\ ${ }^{4}$ Plasma Nanotechnology Research Center, Nagoya University, Nagoya 464-8601, Japan
}

Received December 23, 2015; Accepted April 7, 2016

DOI: 10.3892/ijmm.2016.2574

\begin{abstract}
Cold atmospheric pressure plasma (CAP) is known as a source of biologically active agents, such as reactive oxygen species (ROS) and reactive nitrogen species (RNS). In the present study, we examined the effects of nitrogen $\left(\mathrm{N}_{2}\right)$ on the apoptosis of and changes in gene expression in human lymphoma U937 cells exposed to argon (Ar)-CAP. Enormous amounts of hydroxyl $(\mathrm{OH})$ radicals in aqueous solution
\end{abstract}

Correspondence to: Professor Yoshiaki Tabuchi, Division of Molecular Genetics Research, Life Science Research Center, University of Toyama, 2630 Sugitani, Toyama 930-0194, Japan

E-mail: ytabu@cts.u-toyama.ac.jp

Abbreviations: ADM, adrenomedullin; AHR, aryl hydrocarbon receptor; ANXA1, annexin A1; ATF3, activating transcription factor 3; BAG3, BCL2-associated athanogene 3; BCL6, B-cell CLL/ lymphoma 6; bZIP, basic-region leucine zipper; CAP, cold atmospheric plasma; DNAJB1, DnaJ (HSP40) homolog, subfamily B, member 1; DMPO, 5,5-dimethyl-1-pyrroline-N-oxide; EPR, electron paramagnetic resonance; ERG1, early growth response 1; FITC, fluorescein isothiocyanate; FOS, FBJ murine osteosarcoma viral oncogene homolog; FTH1, ferritin, heavy polypeptide 1; GAPDH, glyceraldehyde-3-phosphate dehydrogenase; HMOX1, heme oxygenase (decycling) 1; HSF1, heat shock transcription factor 1; HSPs, heat shock proteins; HSPA1A/B, heat shock $70 \mathrm{kDa}$ protein 1A/B; HSPA6, heat shock $70 \mathrm{kDa}$ protein 6; ID2, inhibitor of DNA binding 2, dominant negative helix-loop-helix protein; JUN, jun proto-oncogene; JUND, jun D proto-oncogene; KLF, Kruppel-like factor; MXD1, MAX dimerization protein 1; NR4A2, nuclear receptor subfamily 4 group A member 2; PDCD4, programmed cell death 4; PTGS2, prostaglandin-endoperoxide synthase 2; qPCR, quantitative polymerase chain reaction; RNS, reactive nitrogen species; ROS, reactive oxygen species; SDs, standard deviations;SGK1, serum/glucocorticoid regulated kinase 1; TSC22D3, TSC22 domain family member 3; VIM, vimentin

Key words: cold atmospheric pressure plasma, human lymphoma U937 cell, apoptosis, gene network were produced using Ar-CAP generated using a $20 \mathrm{kHz}$ low frequency at $18 \mathrm{kV}$ with a flow rate of $2 \mathrm{l} / \mathrm{min}$. The increase in the levels of ${ }^{\circ} \mathrm{OH}$ radicals was significantly attenuated by the addition of $\mathrm{N}_{2}$ to Ar gas. On the other hand, the level of total nitrate/nitrite in the supernatant was significantly elevated in the $\mathrm{Ar}+\mathrm{N}_{2}$-CAP-exposed U937 cells. When the cells were exposed to Ar-CAP, a significant increase in apoptosis was observed, whereas apoptosis was markedly decreased in the cells exposed to $\mathrm{Ar}+\mathrm{N}_{2}$-CAP. Microarray and pathway analyses revealed that a newly identified gene network containing a number of heat shock proteins (HSPs), anti-apoptotic genes, was mainly associated with the biological function of the prevention of apoptosis. Quantitative PCR revealed that the expression levels of HSPs were significantly elevated in the cells exposed to $\mathrm{Ar}+\mathrm{N}_{2}-\mathrm{CAP}$ than those exposed to Ar-CAP. These results indicate that $\mathrm{N}_{2}$ gas in Ar-CAP modifies the ratio of ROS to RNS, and suppresses the apoptosis induced by Ar-CAP. The modulation of gaseous conditions in CAP may thus prove to be useful for future clinical applications, such as for switching from a sterilizing mode to cytocidal effect for cancer cells.

\section{Introduction}

The therapeutic use of cold atmospheric plasma (CAP) constitutes an emerging interdisciplinary field that capitalizes on the rapidly evolving technology of low-temperature plasma (1-4). Plasma is an at least partially ionized gas and is defined as the fourth state of matter. It is considered to be a mixture of electrons, negative and positive ions, excited gas species, free radicals and electromagnetic radiation. The properties of CAP can be modified by changing various experimental conditions, such as the types of set-ups, the voltage applied, the type of feed gas and the gas flow rate (3-6). It has been demonstrated that CAP is useful in potential applications, such as sterilization (7), wound healing (8), dentistry (9) and tissue regeneration (10). In addition, a recent medical investigation focused on applying CAP to the treatment of cancer (11).

CAP has been reported to effectively suppress cancer cell growth in in vivo experimental models (12-14). There is also 
growing evidence that the exposure of cancer cells to CAP or CAP-activated medium induces apoptosis, and reactive oxygen species (ROS) and/or reactive nitrogen species (RNS) are considered to be effective agents for CAP-induced apoptosis (12-22). In a previous study, CAP produced dose-dependent effects, ranging from increased cell proliferation to apoptosis; these effects were the result of the production of ROS (15). Air-CAP generates a variety of ROS and RNS, and these radicals induce an apoptotic signaling cascade by inducing mitogen-activated protein kinase (MAPK) signaling in cancer cells (17). Adachi et al indicated that hydrogen peroxide $\left(\mathrm{H}_{2} \mathrm{O}_{2}\right)$ and other reactive agents in plasma-activated medium induce cell injury via the mitochondrianuclear apoptotic cascade in cancer cells (21). More recently, we demonstrated that much higher levels of hydroxyl $(\mathrm{OH})$ radicals were produced using argon (Ar)-CAP in an aqueous solution than by using $\mathrm{X}$-irradiation, based on the analysis and quantification of electron paramagnetic resonance (EPR) spectra. Under this condition, Ar-CAP produced intracellular ROS, ${ }^{\circ} \mathrm{OH}$ radicals, $\mathrm{H}_{2} \mathrm{O}_{2}$, which is the recombination product of ${ }^{\circ} \mathrm{OH}$, and hypochlorite ion $\left(\mathrm{OCl}^{-}\right)$in human lymphoma U937 cells (22). Although the generation of ROS induced by CAP and the biological effects of the thus generated ROS have been clarified gradually, the mechanisms of CAP-mediated RNS-cell interactions are not yet fully understood. In this study, we investigated the additional effects of nitrogen $\left(\mathrm{N}_{2}\right)$ in Ar gas on the apoptosis of and changes in gene expression in U937 cells exposed to CAP.

\section{Materials and methods}

Cell culture. Human myelomonocytic lymphoma U937 cells were obtained from the Human Science Research Resources Bank of the Japan Health Sciences Foundation (Tokyo, Japan). The cells were cultured in RPMI-1640 medium (Wako Pure Chemical Industries, Ltd., Osaka, Japan) supplemented with $10 \%$ heat-inactivated fetal bovine serum, and maintained at $37^{\circ} \mathrm{C}$ in humidified air with $5 \% \mathrm{CO}_{2}$ and $95 \%$ air.

Exposure to CAP. CAP was produced using our previously described method (22). The inert gases, Ar and $\mathrm{N}_{2}$, were purchased from Hokusan Co., Ltd. (Toyama, Japan). All gases were of pure grade ( $\geq 99.9 \%$ ). The U937 cells in a well of a 24 -well plate were exposed to Ar-CAP or Ar containing 2.5\% of $\mathrm{N}_{2}\left(\mathrm{Ar}+\mathrm{N}_{2}\right.$-CAP) generated using a $20 \mathrm{kHz}$ low frequency at $18 \mathrm{kV}$ with a flow rate of $2 \mathrm{l} / \mathrm{min}$ for 0 to $3 \mathrm{~min}$ at room temperature. Following exposure to CAP, the cells were cultured for $0-18 \mathrm{~h}$ at $37^{\circ} \mathrm{C}$ in a $\mathrm{CO}_{2}$ incubator. Non-treated cells served as controls.

Optical emissions from CAP. Optical emissions from Ar-CAP were collected using an optic fiber and a lens directed to a position at $8 \mathrm{~mm}$ ahead of CAP. To examine the effects of $\mathrm{N}_{2}$ on the optical emissions of Ar-CAP, $\mathrm{N}_{2}$ was added to the Ar gas at flow rates from 0 to 50 (standard cubic centimeter per minute). The emission was observed using a spectrometer (Shamrock SR-561-B1) and an intensified charge-coupled-device camera (iStar DH734-25F-03) (both from Andor Technology, Ltd., Belfast, UK), as described in a previous study of ours (22).

EPR-spin trapping for the detection of hydroxyl radicals. The detection of ${ }^{\circ} \mathrm{OH}$ radicals following exposure to Ar-CAP or $\mathrm{Ar}+\mathrm{N}_{2}$-CAP was carried out using the EPR-spin trapping with
5,5-dimethyl-1-pyrroline-N-oxide (DMPO; Labotec Co., Ltd., Tokyo, Japan). An aqueous solution containing a spin trap at a concentration of $10 \mathrm{mM}$ was exposed to CAP for up to $120 \mathrm{sec}$. Immediately following exposure, a sample was transferred to a glass capillary tube (VC-HO75P; Terumo, Tokyo, Japan) which was then inserted into a special quartz tube in the cavity of an EPR spectrometer (RFR-30; Radical Research Inc., Tokyo, Japan). The EPR settings were as follows: microwave power, $4 \mathrm{~mW}$; frequency, $9.425 \mathrm{GHz}$; center magnetic field, $329.5 \mathrm{mT}$; and modulation width, $0.1 \mathrm{mT}$. The yields of spin adducts were determined using the stable nitroxide radical 3-carbamoyl-2,2,5,5-tetramethyl-1-pyrroline-1-oxide as a standard at room temperature. The peak heights of the EPR signals were expressed in relative units compared with those of the $\mathrm{Mn}^{2+}$ internal standard, with one unit being equivalent to approximately $7.7 \times 10^{6} \mathrm{M}$ nitroxide radicals (22).

Measurement of nitrite $\left(\mathrm{NO}_{2}\right) /$ nitrate $\left(\mathrm{NO}_{3}\right)$. The U937 cells were exposed to Ar-CAP or $\mathrm{Ar}+\mathrm{N}_{2}$-CAP for 3 min and then the supernatant of the cells was collected by centrifugation. The concentration of total $\mathrm{NO}_{2} / \mathrm{NO}_{3}$ in the supernatant of the cells was measured using an $\mathrm{NO}_{2} / \mathrm{NO}_{3}$ assay kit-C II (Dojindo Laboratories, Kumamoto, Japan) according to the manufacturer's instructions.

Measurements of cell viability and apoptosis. For measuring cell viability, we used a water-soluble tetrazolium salt WST-8 [2-(2-methoxy-4-nitrophenyl)-3-(4-nitrophenyl)-5-(2,4-disulfophenyl)-2H-tetrazolium, monosodium salt]-based assay (Cell Counting kit-8; Dojindo Laboratories). In brief, the cells were incubated in $110 \mu \mathrm{l}$ RPMI-1640 medium containing 9.1\% (v/v) of WST-8 reagent in a $96-$-well cell culture plate at $37^{\circ} \mathrm{C}$. Two hours later, the produced formazan dye concentration was determined from the absorbance at $450 \mathrm{~nm}$ using a microplate reader (23). The level of apoptosis was determined using an Annexin V-FITC kit (Immunotech, Marseille, France). Fluorescein isothiocyanate (FITC)-labeled Annexin V and propidium iodide were added to the cell suspension. Following incubation for $20 \mathrm{~min}$ in the dark, the cells were analyzed using a flow cytometer (Epics XL; Beckman Coulter K.K., Tokyo, Japan). Apoptosis was expressed as the sum of early apoptotic and secondary necrotic fractions.

RNA isolation. For global-scale gene expression and quantitative polymerase chain reaction (qPCR) analyses, total RNA was extracted from the cells using a NucleoSpin ${ }^{\circledR}$ RNA isolation kit (Macherey-Nagel GmbH \& Co., Düren, Germany) along with on-column DNase I treatment. RNA quality was analyzed using a Bioanalyzer 2100 (Agilent Technologies, Inc., Santa Clara, CA, USA).

Global-scale gene expression analysis. Global-scale gene expression analysis was carried out using a GeneChip ${ }^{\circledR}$ microarray system with a Human Genome U133-plus 2.0 array, which was spotted with 54,675 probe sets (Affymetrix Inc., Santa Clara, CA, USA) according to the manufacturer's instructions. The obtained hybridization intensity data were analyzed using GeneSpring ${ }^{\circledR}$ GX (Agilent Technologies, Inc.) to extract the significant genes. To examine gene ontology, including biological processes, cellular components, molecular functions 

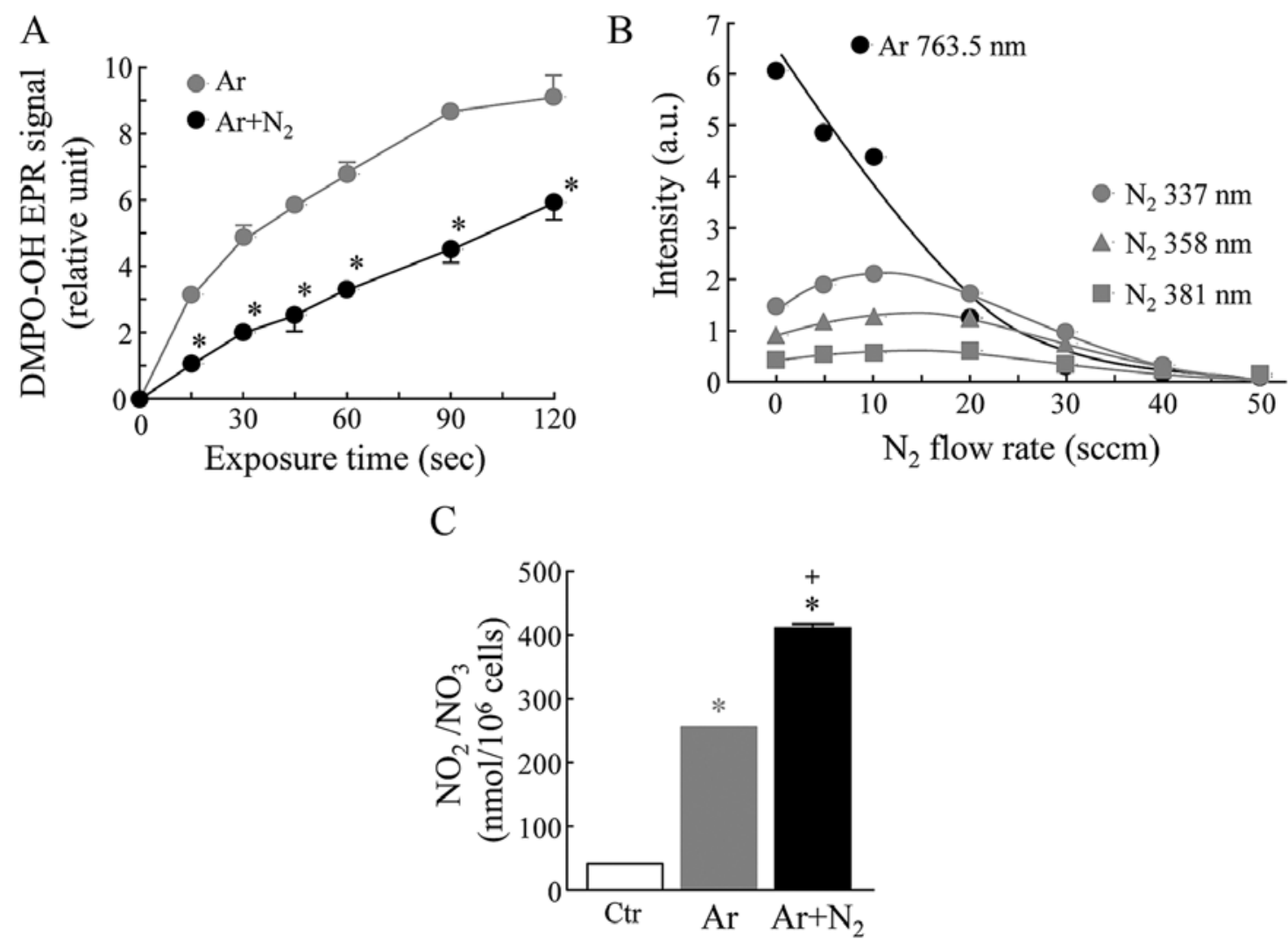

Figure 1. (A) Hydroxyl radical formation induced by cold atmospheric plasma (CAP). Argon (Ar)-CAP or Ar + Nitrogen $\left(\mathrm{N}_{2}\right)(2.5 \%)$-CAP generated by using a $20 \mathrm{kHz}$ low frequency at $18 \mathrm{kV}$ with a flow rate of $2 \mathrm{l} / \mathrm{min}$ was applied to aqueous solutions for 0 to $120 \mathrm{sec}$. Electron paramagnetic resonance (EPR)-spin trapping experiments were performed with DMPO as a spin trap for detection of ${ }^{\circ} \mathrm{OH}$ in aqueous solution. Data are presented as the means $\pm \mathrm{SDs}\left(\mathrm{n}=3\right.$ ). ${ }^{*} \mathrm{P}<0.05$ vs. each group of Ar-treated cells (Student's t-test). (B) The effects of $\mathrm{N}_{2}$ on the intensity of optical emissions generated by Ar-CAP. $\mathrm{N}_{2}$ at flow rates from 0 to 50 [standard cubic centimeter per minute (sccm)] were added to Ar. Ar $763.5 \mathrm{~nm}$, emission spectra from excited states of Ar; $\mathrm{N}_{2} 337,358 \mathrm{and} 381 \mathrm{~nm}$, emission spectra from excited $\mathrm{N}_{2}$. (C) Nitrite/nitrate formation induced by Ar-CAP or Ar $+\mathrm{N}_{2}$-CAP. The supernatant was collected from the U937 cells exposed to $\operatorname{Ar}-\mathrm{CAP}(\mathrm{Ar})$ or $\mathrm{Ar}+\mathrm{N}_{2}(2.5 \%)$-CAP $\left(\mathrm{Ar}+\mathrm{N}_{2}\right)$ for $3 \mathrm{~min}$. The concentration of total $\mathrm{NO}_{2} / \mathrm{NO}_{3}$ was measured by using a commercial colorimetric assay kit. Non-treated cells served as controls (Ctr). Data are presented as the means \pm SDs ( $n=3)$. ${ }^{*} \mathrm{P}<0.05$ vs. $\mathrm{Ctr}$; ${ }^{+} \mathrm{P}<0.05$ vs Ar-CAP-exposed cells (Student's t-test).

and gene networks, the obtained data were analyzed using Ingenuity ${ }^{\circledR}$ Pathway Analysis tools (Ingenuity Systems Inc., Mountain View, CA, USA), as previously described $(23,24)$.

Measurement of mRNA levels by $q P C R$. The mRNA levels in the cells were determined following exposure to $\mathrm{CAP}$ for $2 \mathrm{~min}$ followed by culture at $37^{\circ} \mathrm{C}$ for $3 \mathrm{~h}$ using an Mx3005P real-time PCR system (Agilent Technologies, Inc.) with using SYBR Premix Ex Taq or Premix Ex Taq (for the use of TaqMan probes) (both from Takara Bio Inc., Shiga, Japan). The specific primers and probes for BCL2-associated athanogene 3 (BAG3), DnaJ [heat shock protein (HSP)40] homolog, subfamily B, member 1 (DNAJB1), early growth response 1 (ERG1), glyceraldehyde-3-phosphate dehydrogenase (GAPDH), heme oxygenase (decycling) 1 (HMOX1), heat shock $70 \mathrm{kDa}$ protein 1A/B (HSPA1A/B) and heat shock $70 \mathrm{kDa}$ protein 6 (HSPA6 or HSP70B') were designed based on the database. GAPDH was used as a control for normalization, as previously described (24-26).

Statistical analysis. Data are presented as the means \pm standard deviations (SDs). Differences between pairs of data sets were analyzed using Student's t-test, with values of $\mathrm{P}<0.05$ considered to indicate statistically significant differences.

\section{Results}

Hydroxyl radical and $\mathrm{NO}_{2} / \mathrm{NO}_{3}$ formations induced by exposure to $C A P$. EPR-spin trapping experiments were carried out with $\mathrm{DMPO}$ as a spin trap to detect ${ }^{\circ} \mathrm{OH}$ radicals in aqueous solution exposed to Ar-CAP or $\mathrm{Ar}+\mathrm{N}_{2}(2.5 \%)$-CAP generated by using a $20 \mathrm{kHz}$ low frequency at $18 \mathrm{kV}$ with a flow rate of $2 \mathrm{l} / \mathrm{min}$ at room temperature. The formations of ${ }^{\circ} \mathrm{OH}$ radicals as measured by the amount of DMPO-OH adducts were markedly increased in the aqueous DMPO solutions exposed to Ar-CAP in an exposure time-dependent manner. When the aqueous DMPO solutions were exposed to $\mathrm{Ar}+\mathrm{N}_{2}$-CAP, the levels of DMPO-OH adducts were significantly reduced to approximately $50 \%$ of the levels induced by Ar-CAP (Fig. 1A). The effects of $\mathrm{N}_{2}$ on the intensity of optical emissions generated by Ar-CAP were also investigated. In our previous study, we already confirmed that the emission lines and bands from excited $\mathrm{Ar}$ and $\mathrm{N}_{2}$ were mainly observed at 696.5-852.1 and 316.0-416.0 nm, respectively (22). The intensity of emission spectra from excited Ar at $763.5 \mathrm{~nm}$ was readily decreased depending on the increase in the amount of $\mathrm{N}_{2}$ in Ar gas. On the other hand, a slight and transient increase in the intensity of emission spectra from excited $\mathrm{N}_{2}$ at 337.0, 358.0 and $381 \mathrm{~nm}$ was observed in the $\mathrm{N}_{2}$-exposed samples (Fig. 1B). A much 
A

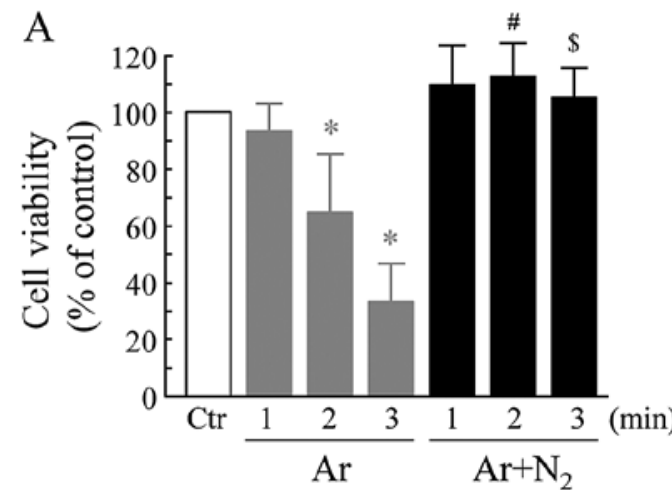

B

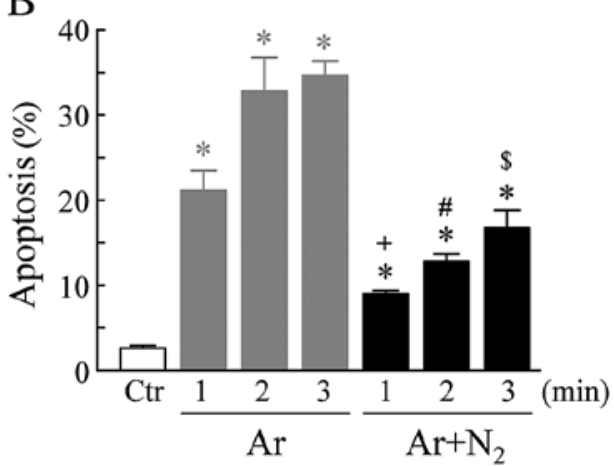

Figure 2. Effects of argon cold atmospheric plasma (Ar-CAP) and Ar + Nitrogen $\left(\mathrm{N}_{2}\right)$-CAP on (A) cell viability and (B) apoptosis. The cells were exposed to $\operatorname{Ar}-\mathrm{CAP}(\mathrm{Ar})$ or $\mathrm{Ar}+\mathrm{N}_{2}(2.5 \%)$-CAP $\left(\mathrm{Ar}+\mathrm{N}_{2}\right.$ ) for 1-3 min. Eighteen or six hours later, (A) cell viability or (B) apoptosis were measured using a cell counting kit-8 or an Annexin V-fluorescein isothiocyanate (FITC) kit, respectively. Non-treated cells served as controls (Ctr). Ctr=100\%. Data are presented as the means \pm SDs $(\mathrm{n}=3-4) .{ }^{*} \mathrm{P}<0.05$ vs. Ctr; ${ }^{+} \mathrm{P}<0.05$ vs. Ar for $1 \mathrm{~min} ;{ }^{\#} \mathrm{P}<0.05 \mathrm{vs}$. Ar for $2 \mathrm{~min} ;{ }^{\$} \mathrm{P}<0.05$ vs. Ar for 3 min (Student's t-test).

A

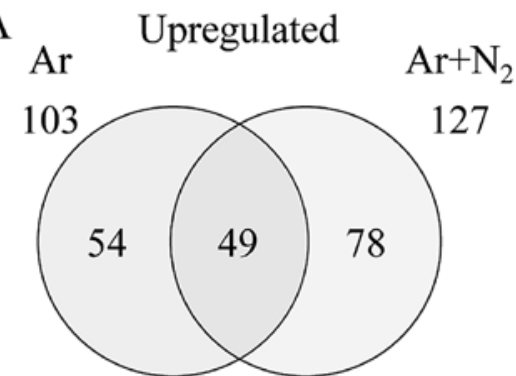

B

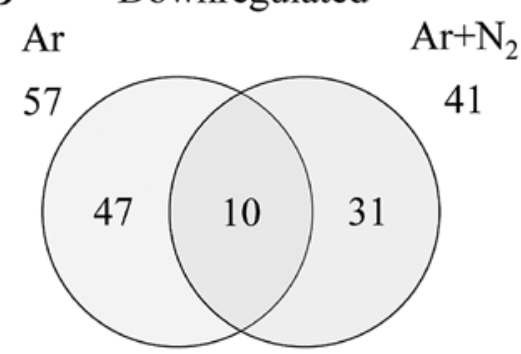

Figure 3. Venn diagram of genes that were differentially expressed. The cells were exposed to argon cold atmospheric plasma (Ar-CAP) (Ar) or $\mathrm{Ar}+$ Nitrogen $\left(\mathrm{N}_{2}\right)(2.5 \%)$-CAP $\left(\mathrm{Ar}+\mathrm{N}_{2}\right)$ for $2 \mathrm{~min}$, followed by culture at $37^{\circ} \mathrm{C}$ for $3 \mathrm{~h}$. Gene expression analysis of the probe sets that were upregulated and downregulated by a factor of $\geq 2.0$ was conducted using GeneSpring ${ }^{\circledR}$ GX software. The diagram shows the number of specifically and commonly expressed genes affected by CAP. (A) Upregulated genes; (B) downregulated genes. The experiments were repeated twice.

greater amount of total $\mathrm{NO}_{2} / \mathrm{NO}_{3}\left(255.0 \pm 0.87 \mathrm{nmol} / 10^{6}\right.$ cells, mean $\pm \mathrm{SD}$ ) in the supernatant was detected in the human lymphoma U937 cells exposed to Ar-CAP compared to the control cells (41.7 \pm 0.49 ) (Fig. 1C). Moreover, a further elevation in the amount of total $\mathrm{NO}_{2} / \mathrm{NO}_{3}\left(410.3 \pm 4.0 \mathrm{nmol} / 10^{6}\right.$ cells, mean $\pm \mathrm{SD}$ ) was observed in the $\mathrm{Ar}+\mathrm{N}_{2}$-CAP-exposed cells.

Effects of Ar- and Ar $+N_{2}-C A P$ on cell viability and apoptosis. The viability or apoptosis of the cells following exposure to CAP for 1 to $3 \mathrm{~min}$ followed by culture at $37^{\circ} \mathrm{C}$ for 18 or 6 h, respectively, was investigated. As demonstrated in Fig. 2, Ar-CAP significantly decreased cell viability in an exposuretime dependent manner. By contrast, cell viability was not affected by the exposure of the cells to $\mathrm{Ar}+\mathrm{N}_{2}$-CAP (Fig. 2A).
A significant induction of apoptosis was observed in the cells exposed to Ar-CAP in an exposure-time dependent manner. The addition of $\mathrm{N}_{2}$ to the Ar gas markedly suppressed Ar-CAPinduced apoptosis, and the percentage of suppression was approximately 50\% (Fig. 2B).

Gene expression analysis. The gene expression patterns in the cells following exposure to CAP for $2 \mathrm{~min}$ followed by culture at $37^{\circ} \mathrm{C}$ for $3 \mathrm{~h}$ was monitored using a GeneChip ${ }^{\circledR}$ microarray system. The complete lists of probe sets from all samples are deposited at the Gene Expression Omnibus, a public data base (accession no. GSE76022). Gene expression analysis using GeneSpring ${ }^{\circledR}$ software revealed that a number of genes were differentially expressed by a factor of $\geq 2.0$ between the cells exposed to Ar- or Ar $+\mathrm{N}_{2}$-CAP and the control cells. The numbers of genes expressed in either group or commonly in both groups are shown in the Venn diagram in Fig. 3. The total numbers of genes that were found to be differentially expressed were 160 (103 up- and 57 downregulated genes) and 168 (127 up- and 41 downregulated genes) in the Ar- and $\mathrm{Ar}+\mathrm{N}_{2}$-CAP groups, respectively. In addition, the numbers of commonly up- and downregulated genes were 49 and 10 , respectively (Fig. 3).

Identification of gene networks associated with apoptosis. To identify gene networks associated with CAP-induced apoptosis, functional category and pathway analyses were conducted by using Ingenuity ${ }^{\circledR}$ Pathway Analysis tools. A number of functionally annotated genes were identified among both the upregulated and downregulated genes of the Ar- and $\mathrm{Ar}+\mathrm{N}_{2}$-CAP groups. We identified two gene networks, designated as the pro-apoptosis gene network and the anti-apoptosis gene network, in the functionally annotated and upregulated genes of the Ar-CAP- and Ar $+\mathrm{N}_{2}$-CAPexposed groups, and showed that these were mainly associated with the biological functions of the induction and prevention of apoptosis, respectively. The pro-apoptosis gene network included 8 genes, namely Annexin A1 (ANXA1), activating transcription factor 3 (ATF3), FBJ murine osteosarcoma viral oncogene homolog (FOS), inhibitor of DNA binding 2, dominant negative helix-loop-helix protein (ID2), jun protooncogene (JUN), Kruppel-like factor 4 (KLF4), programmed 
A

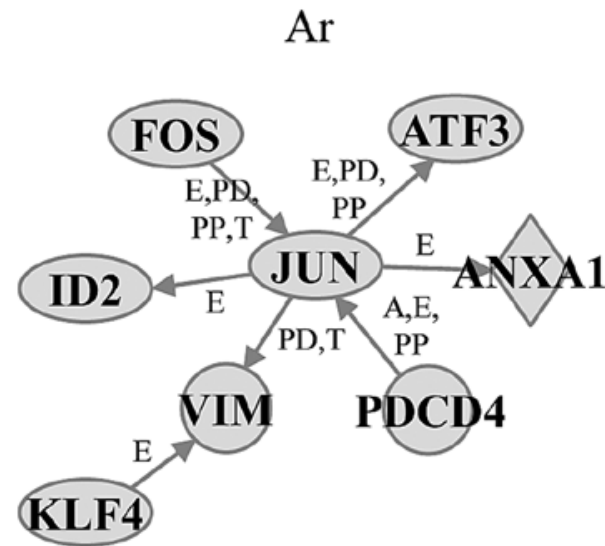

B $\quad \mathrm{Ar}+\mathrm{N}_{2}$

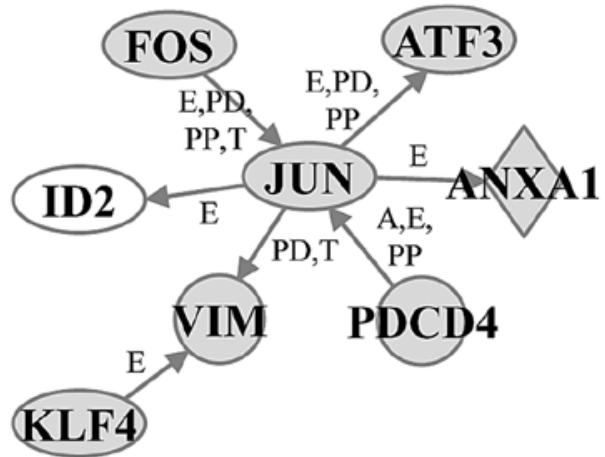

\section{Edge labels}

A, activation/deactivation
$\mathbf{E}$, expression
P, phosphorylation/dephosphorylation
PD, protein-DNA binding
PP, protein-protein binding
T, transcription

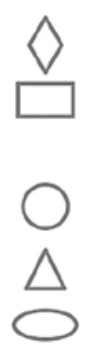

enzyme
ligand-dependent
nuclear receptor
Others
phosphatase
transcription regulator

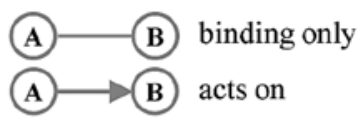

$\longrightarrow$ direct interaction

upregulated

no change or downregulated

Figure 4. The pro-apoptosis gene network. Upregulated genes in argon cold atmospheric plasma (Ar-CAP)-exposed cells were analyzed by Ingenuity ${ }^{\circledR}$ Pathways Analysis tools. The expression levels of genes in Ar- or Ar + Nitrogen $\left(\mathrm{N}_{2}\right)(2.5 \%)$-CAP $\left(\mathrm{Ar}+\mathrm{N}_{2}\right)$-exposed cells are shown in the (A) gene network Ar or $(\mathrm{B})$ gene network $\mathrm{Ar}+\mathrm{N}_{2}$, respectively. In the graphical representation of the networks, nodes refer to genes and edges refer to the biological relationships between nodes. The node color indicates the expression level of genes. Nodes and edges are displayed using various shapes and labels reflecting the functional class of each gene and the nature of the relationships involved, respectively.

cell death 4 (PDCD4), and vimentin (VIM). The expression levels of 7 of these 8 genes, with ID2 being the exception, were increased under both the Ar-CAP- and $\mathrm{Ar}+\mathrm{N}_{2}$-CAP exposure conditions. A significant elevation in the ID2 levels was only observed in the cells exposed to Ar-CAP (Fig. 4). The anti-apoptosis gene network contained 17 genes, including HSPs, DNAJB1, HMOX1, HSPA1A/B and HSPA6, and adrenomedullin (ADM), aryl hydrocarbon receptor (AHR), BAG3, B-cell CLL/lymphoma 6 (BCL6), EGR1, ferritin, heavy polypeptide 1 (FTH1), jun D proto-oncogene (JUND), KLF2, MAX dimerization protein 1 (MXD1), nuclear receptor subfamily 4 group A member 2 (NR4A2), prostaglandin-endoperoxide synthase 2 (PTGS2), serum/ glucocorticoid regulated kinase 1 (SGK1) and TSC22 domain family member 3 (TSC22D3). In this network, the expression levels of 7 genes, AHR, BCL6, FTH1, JUND, MXD1, NR4A2 and TSC22D3, were significantly lower in the Ar-CAP-exposed cells than in the $\mathrm{Ar}+\mathrm{N}_{2}$-CAP-exposed cells. However, the other 10 genes remained significantly elevated under both conditions (Fig. 5).

Effects of Ar-and $\mathrm{Ar}+\mathrm{N}_{2}$-CAP on gene expression, as shown by $q P C R$. The mRNA levels in the cells following exposure to $\mathrm{CAP}$ for $2 \mathrm{~min}$ followed by culture at $37^{\circ} \mathrm{C}$ for $3 \mathrm{~h}$ was monitored by using real-time qPCR. We selected 6 genes, BAG3, DNAJB1, EGR1, HMOX1, HSPA1A/B and HSPA6, from the anti-apoptosis gene network. The expression levels of these 6 genes were significantly elevated in the Ar-CAP-exposed cells compared to the control cells (Fig. 6). Under the Ar $+\mathrm{N}_{2}-\mathrm{CAP}$ exposure conditions, a further increase in the expression levels of these genes was observed in comparison with those under the Ar-CAP exposure conditions.

\section{Discussion}

CAP is well known as a source of biologically active agents, such as ROS and RNS (1-4), and its characteristics can be modified by altering the experimental conditions (3-6). In the present study, enormous amounts of ${ }^{\circ} \mathrm{OH}$ radicals in aqueous solution were produced using an Ar-CAP-generating system as reported previously (22). Moreover, Ar gas modification by the addition of $\mathrm{N}_{2}$ resulted in decreased levels of ${ }^{\circ} \mathrm{OH}$ radicals in the aqueous solutions and increased levels of $\mathrm{NO}_{2} / \mathrm{NO}_{3}$ in the supernatant of human lymphoma U937 cells, indicating that $\mathrm{N}_{2}$ gas in Ar-CAP modified the ratio of ROS to RNS. In the system used in this study and in our previous study, a certain amount of $\mathrm{NO}_{2} / \mathrm{NO}_{3}$ was detected even if Ar-CAP was used, suggesting that the effluent Ar gas mixed with atmospheric air in remote regions can influence the CAP characteristics (22).

There is accumulating experimental evidence that CAP is an effective agent to suppress cancer cell growth and to induce apoptosis under both in vivo and in vitro models, and CAP-produced ROS and/or RNS play a principal role in its anticancer effects (12-22). In general, relatively low levels of ROS are essential to maintain the physiological homeostasis of the cell. On the other hand, increased levels of ROS may 

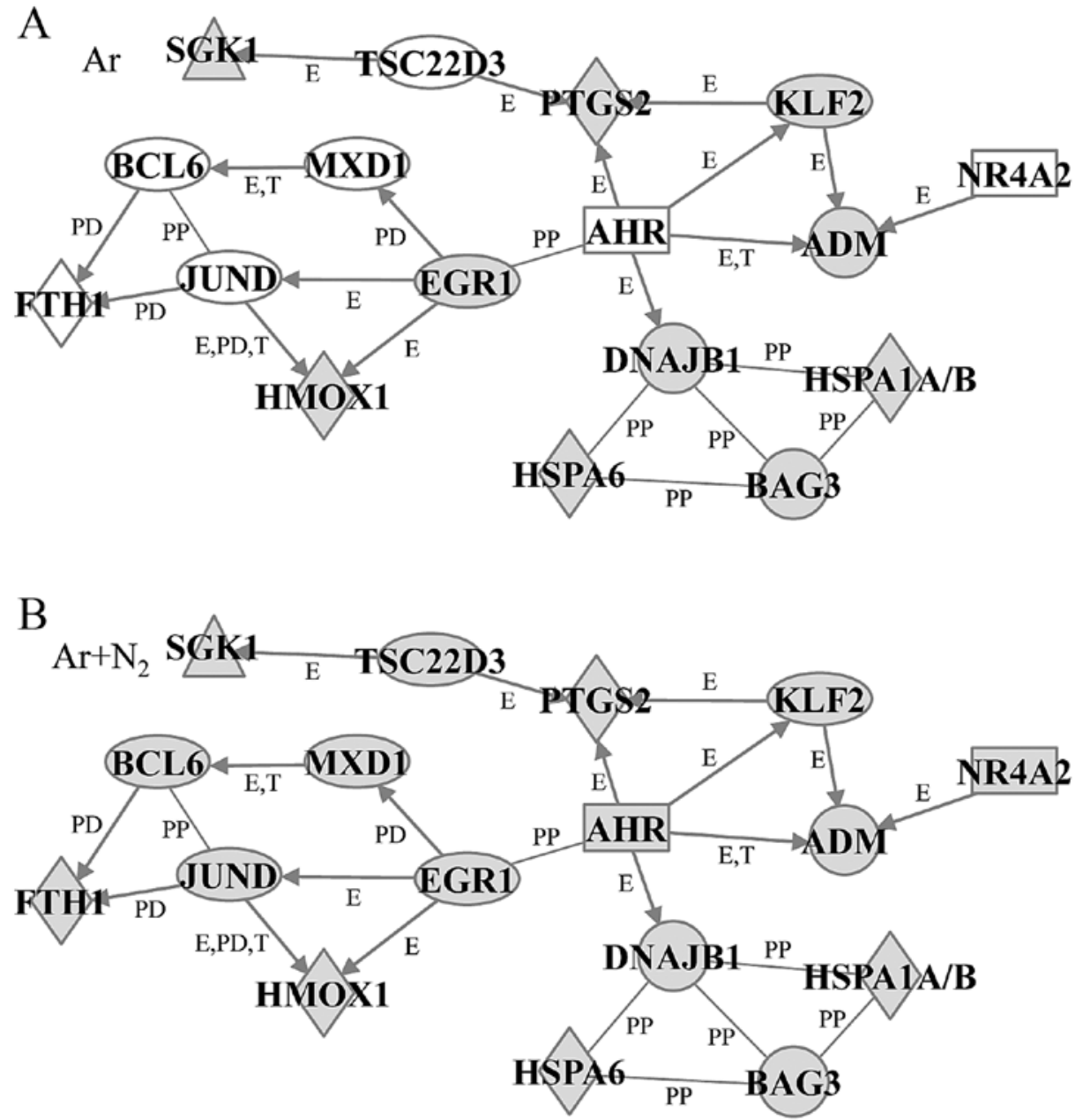

Figure 5. The anti-apoptosis gene network. Upregulated genes in Ar + Nitrogen $\left(\mathrm{N}_{2}\right)(2.5 \%)$-CAP $\left(\right.$ Ar $\left.+\mathrm{N}_{2}\right)$-exposed cells were analyzed by Ingenuity ${ }^{\circledR}$ Pathways Analysis tools. The expression levels of genes in argon cold atmospheric plasma (Ar-CAP)- or Ar $+\mathrm{N}_{2}$-exposed cells are shown in the (A) gene network Ar or (B) gene network $\mathrm{Ar}+\mathrm{N}_{2}$, respectively. For an explanation of the symbols and letters, see Fig. 4.

be detrimental and lead to cell death, including apoptosis (27). Kalghatgi et al (15) suggested that the dose-dependent effects of CAP, which range from increased cell proliferation to apoptosis, are related to the amount of ROS (15). In our previous studies using U937 cells, the degree of apoptosis was well associated with the degree of produced ROS under a variety of experimental conditions (28-30). In the present study, a marked induction of apoptosis was observed in the U937 cells exposed to Ar-CAP, whereas the addition of $\mathrm{N}_{2}$ to the Ar gas significantly suppressed the Ar-CAP-induced increase in apoptosis. These results suggest that these inhibitory effects of $\mathrm{N}_{2}$ may be due to a decrease in ROS and/or increase in RNS levels.

To elucidate the molecular mechanisms underlying CAP-induced apoptosis, gene expression patterns were investigated using a combination of high-density oligonucleotide microarray and computational gene expression analysis tools. In the present study, we identified a number of genes that exhibited $\mathrm{a} \geq 2$.0-fold difference in expression between the cells exposed to Ar- or $\mathrm{Ar}+\mathrm{N}_{2}$-CAP and the control cells. In addition, by using Ingenuity ${ }^{\circledR}$ pathway analysis, we discovered a significant gene network, herein designated as the pro-apoptosis gene network, that was associated with the biological function of the induction of apoptosis. In this network, ANXA1 (31), ATF3 (32), FOS (33), JUN (34) and
KLF4 (35) have been reported to function as pro-apoptotic molecules in a wide variety of cell types, including cancer cells. JUN, ATF3 and FOS belong to the basic-region leucine zipper (bZIP) transcription factor family, and the homo- and heterodimeric bZIP protein complexes act as activators and suppressors of transcription. For example, the JUN and FOS proteins form the heterodimer of the activating protein-1 (AP-1) complex (36). These three transcription factors have been shown to be markedly upregulated in U937 cells undergoing heat stress-induced apoptosis (24). Previous findings have suggested that the overexpression of JUN in combination with FOS enhances the sensitivity of keratinocytes to apoptosis (37). In this network, almost all genes were upregulated under both the Ar- and $\mathrm{Ar}+\mathrm{N}_{2}$-CAP conditions, with the single exception being ID2, whose expression was observed only under the Ar-CAP conditions (Fig. 4). The elevation of gene expression in the pro-apoptosis gene network may have been closely associated with the induction of apoptosis by CAP in U937 cells.

In addition, we successfully identified the anti-apoptosis gene network, which was associated with the biological function of the prevention of apoptosis from upregulated genes in $\mathrm{Ar}+\mathrm{N}_{2}-\mathrm{CAP}$-exposed cells (Fig. 5). In this network, 7 genes, including AHR (38), FTH1 (39) and NR4A2 (40), which have 

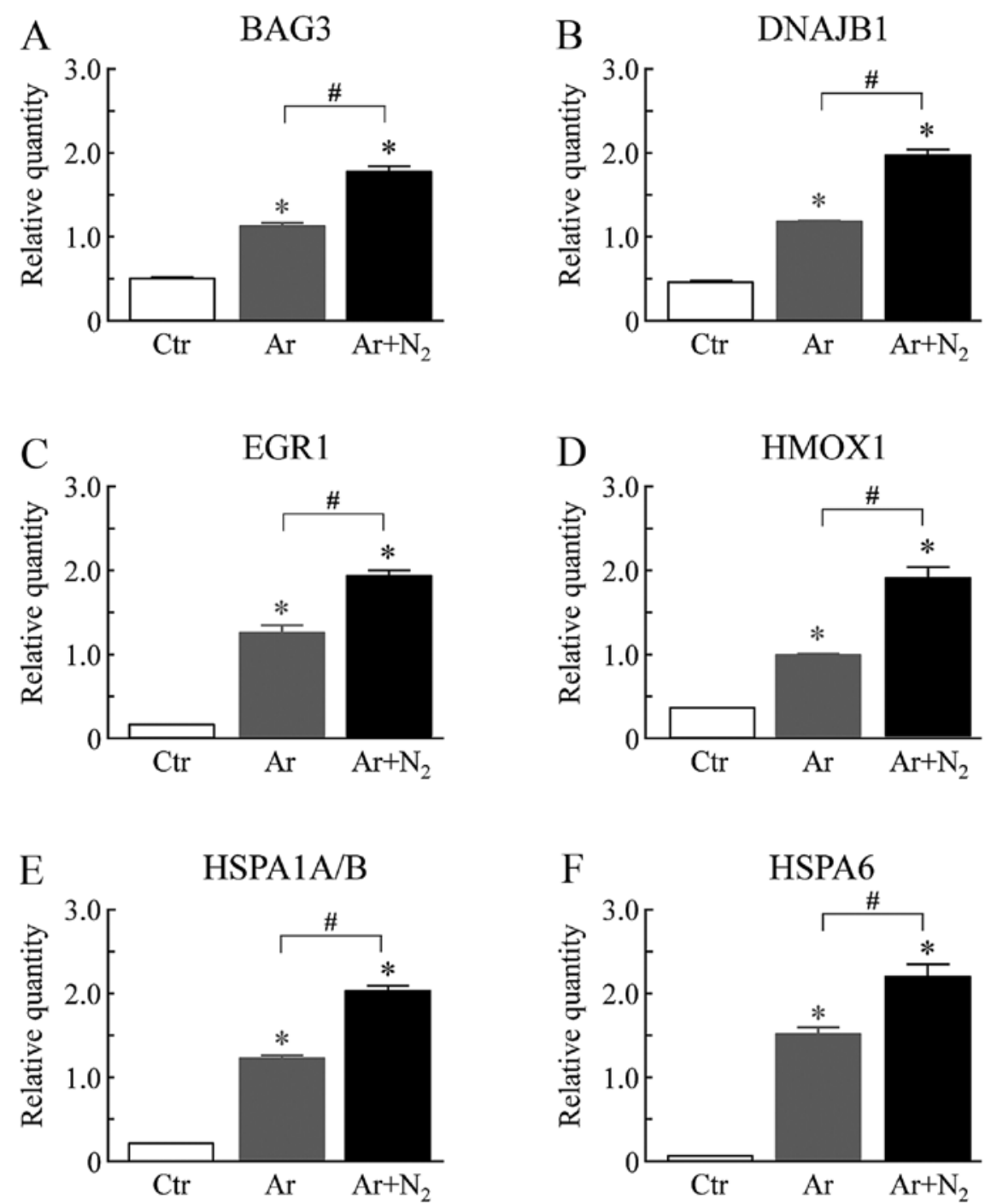

Figure 6. Effects of argon cold atmospheric plasma (Ar-CAP) and Ar + Nitrogen $\left(\mathrm{N}_{2}\right)$-CAP on gene expression determined by qPCR. Following the exposure of the cells to $\mathrm{Ar}-\mathrm{CAP}(\mathrm{Ar})$ or $\mathrm{Ar}+\mathrm{N}_{2}(2.5 \%)$-CAP $\left(\mathrm{Ar}+\mathrm{N}_{2}\right)$ for $2 \mathrm{~min}$, the cells were cultured for $3 \mathrm{~h}$ at $37^{\circ} \mathrm{C}$. qPCR was then performed. (A) BCL2-associated athanogene 3 (BAG3); (B) DnaJ (HSP40) homolog, subfamily B, member 1 (DNAJB1); (C) EGR1; (D) heme oxygenase (decycling) 1 (HMOX1); (E) heat shock $70 \mathrm{kDa}$ protein 1A/B (HSPA1A/B); (F) heat shock $70 \mathrm{kDa}$ protein 6 (HSPA6). Each expression level was normalized to the GAPDH expression level. Non-treated cells served as controls (Ctr). Data are presented as the means $\pm \mathrm{SDs}(\mathrm{n}=4)$. ${ }^{\mathrm{P}}<0.05$ vs. $\mathrm{Ctr} ;{ }^{\#} \mathrm{P}<0.05$ vs. Ar-CAP-exposed cells (Student's $t$-test).

been reported to inhibit apoptosis, were expressed at lower levels under the Ar-CAP conditions compared to the $\mathrm{Ar}+\mathrm{N}_{2}-\mathrm{CAP}$ conditions. The downregulation of these genes may contribute to the ability to induce apoptosis induced by Ar-CAP. The antiapoptosis gene network also contained several HSPs, DNAJB1, HMOX1, HSPA1A/B and HSPA6, and BAG3. Of note, qPCR clearly demonstrated that the expression levels of these genes were significantly higher under either the Ar- or $\mathrm{Ar}+\mathrm{N}_{2}-\mathrm{CAP}$ conditions than under the control conditions (Fig. 6). HSPs and BAG3, a co-chaperone of HSP70, are primarily regulated by heat shock transcription factor 1 (HSF1), and these proteins function as anti-apoptotic molecules against various types of stress, particularly heat $(41,42)$. DNAJB1 (43), HMOX1 (44), HSPA1A/B (43), HSPA6 (45) and BAG3 (46) are known to participate in the prevention of apoptosis. Previous findings have indicated that very weak but nonetheless significant heatinducible heat shock element-binding activity of HSF1 was observed when cells were incubated at $39^{\circ} \mathrm{C}$ for $20 \mathrm{~min}$ (47).
In the same CAP system as used herein and in our previous study, temperature increases of $1.7 \pm 0.2^{\circ} \mathrm{C}$ (mean $\pm \mathrm{SD}$ ) and $2.3 \pm 0.2^{\circ} \mathrm{C}$ were observed following 2 and $5 \mathrm{~min}$ of exposure at room temperature, respectively (22). It is also known that HSF1 can be activated directly by oxidative stress (48). Therefore, we considered that the induction of HSP-related genes may have been due to the activation of HSF1 by ROS, rather than to an increase in temperature under both CAP conditions. In the present study, further elevations in the total amount of $\mathrm{NO}_{2} /$ $\mathrm{NO}_{3}$ and the overexpression of HSP-related genes were detected in the cells exposed to $\mathrm{Ar}+\mathrm{N}_{2}-\mathrm{CAP}$ (Figs. 1C and 6). Previous studies have indicated that nitric oxide (NO) is generated by CAP with atmospheric $\mathrm{N}_{2}$ and is then rapidly converted to other species including NOX (49). In previous studies, NO has been reported to induce Hsp70 expression and lead to cytoprotection in cells $(50,51)$ and the induction of HSP70 expression by NO has shown to be regulated by HSF1 activation (52). Under our CAP conditions, the induction of HSPs via NO generation 
may have participated in the suppression of Ar-CAP-induced apoptosis by $\mathrm{N}_{2}$.

The findings of the present study provide insight toward the eventual elucidation of the molecular mechanisms underlying the CAP-induced apoptosis of cancer cells. The modulation of gaseous conditions in CAP may be useful for future clinical applications, such as when switching from a sterilizing mode to a cytocidal effect for the treatment of cancer.

\section{Acknowledgements}

This study was supported in part by a Grant-in-Aid for Scientific Research on Innovative Areas, grant nos. 25108503 and 15H00892 from the Ministry of Education, Culture, Sports, Science and Technology of Japan.

\section{References}

1. Hoffmann C, Berganza C and Zhang J: Cold Atmospheric Plasma: Methods of production and application in dentistry and oncology. Med Gas Res 3: 21, 2013.

2. Mai-Prochnow A, Murphy AB, McLean KM, Kong MG and Ostrikov KK: Atmospheric pressure plasmas: Infection control and bacterial responses. Int J Antimicrob Agents 43: 508-517, 2014.

3. Arjunan KP, Sharma VK and Ptasinska S: Effects of atmospheric pressure plasmas on isolated and cellular DNA-a review. Int J Mol Sci 16: 2971-3016, 2015.

4. Isbary G, Shimizu T, Li YF, Stolz W, Thomas HM, Morfill GE and Zimmermann JL: Cold atmospheric plasma devices for medical issues. Expert Rev Med Devices 10: 367-377, 2013.

5. Joh HM, Choi JY, Kim SJ, Chung TH and Kang TH: Effect of additive oxygen gas on cellular response of lung cancer cells induced by atmospheric pressure helium plasma jet. Sci Rep 4: 6638,2014

6. Hertwig C, Steins V, Reineke K, Rademacher A, Klocke M, Rauh C and Schlüter O: Impact of surface structure and feed gas composition on Bacillus subtilis endospore inactivation during direct plasma treatment. Front Microbiol 6: 774, 2015.

7. Brun P, Brun P, Vono M, Venier P, Tarricone E, Deligianni V, Martines E, Zuin M, Spagnolo S, Cavazzana R, et al: Disinfection of ocular cells and tissues by atmospheric-pressure cold plasma. PLoS One 7: e33245, 2012

8. Schmidt A, Dietrich S, Steuer A, Weltmann KD, von Woedtke T, Masur K and Wende K: Non-thermal plasma activates human keratinocytes by stimulation of antioxidant and phase II pathways. J Biol Chem 290: 6731-6750, 2015.

9. Duske K, Koban I, Kindel E, Schröder K, Nebe B, Holtfreter B, Jablonowski L, Weltmann KD and Kocher T: Atmospheric plasma enhances wettability and cell spreading on dental implant metals. J Clin Periodontol 39: 400-407, 2012.

10. Steinbeck MJ, Chernets N, Zhang J, Kurpad DS, Fridman G, Fridman A and Freeman TA: Skeletal cell differentiation is enhanced by atmospheric dielectric barrier discharge plasma treatment. PLoS One 8: e82143, 2013.

11. Hirst AM, Frame FM, Maitland NJ and O'Connell D: Low temperature plasma: A novel focal therapy for localized prostate cancer? BioMed Res Int 2014: 878319, 2014.

12. Partecke LI, Evert K, Haugk J, Doering F, Normann L, Diedrich S, Weiss FU, Evert M, Huebner NO, Guenther C, et al: Tissue tolerable plasma (TTP) induces apoptosis in pancreatic cancer cells in vitro and in vivo. BMC Cancer 12: 473, 2012.

13. Walk RM, Snyder JA, Srinivasan P, Kirsch J, Diaz SO, Blanco FC Shashurin A, Keidar M and Sandler AD: Cold atmospheric plasma for the ablative treatment of neuroblastoma. J Pediatr Surg 48: 67-73, 2013.

14. Utsumi F, Kajiyama H, Nakamura K, Tanaka H, Mizuno M, Ishikawa K, Kondo H, Kano H, Hori M and Kikkawa F: Effect of indirect nonequilibrium atmospheric pressure plasma on antiproliferative activity against chronic chemo-resistant ovarian cancer cells in vitro and in vivo. PLoS One 8: e81576, 2013.

15. Kalghatgi S, Kelly CM, Cerchar E, Torabi B, Alekseev O, Fridman A, Friedman G and Azizkhan-Clifford J: Effects of nonthermal plasma on mammalian cells. PLoS One 6: e16270, 2011.
16. Zhao S, Xiong Z, Mao X, Meng D, Lei Q, Li Y, Deng P, Chen M, Tu M, Lu X, et al: Atmospheric pressure room temperature plasma jets facilitate oxidative and nitrative stress and lead to endoplasmic reticulum stress dependent apoptosis in HepG2 cells. PLoS One 8: e73665, 2013.

17. Ahn HJ, Kim KI, Hoan NN, Kim CH, Moon E, Choi KS, Yang SS and Lee JS: Targeting cancer cells with reactive oxygen and nitrogen species generated by atmospheric-pressure air plasma. PLoS One 9: e86173, 2014.

18. Thiyagarajan M, Anderson $\mathrm{H}$ and Gonzales XF: Induction of apoptosis in human myeloid leukemia cells by remote exposure of resistive barrier cold plasma. Biotechnol Bioeng 111: 565-574, 2014.

19. Ma Y, Ha CS, Hwang SW, Lee HJ, Kim GC, Lee KW and Song K: Non-thermal atmospheric pressure plasma preferentially induces apoptosis in p53-mutated cancer cells by activating ROS stressresponse pathways. PLoS One 9: e91947, 2014.

20. Kaushik N, Kumar N, Kim CH, Kaushik NK and Choi EH: Dielectric barrier discharge plasma efficiently delivers an apoptotic response in human monocytic lymphoma. Plasma Process Polym 11: 1175-1187, 2014.

21. Adachi T, Tanaka H, Nonomura S, Hara H, Kondo S and Hori M: Plasma-activated medium induces A549 cell injury via a spiral apoptotic cascade involving the mitochondrial-nuclear network. Free Radic Biol Med 79: 28-44, 2015.

22. Uchiyama H, Zhao QL, Hassan MA, Andocs G, Nojima N, Takeda K, Ishikawa K, Hori M and Kondo T: EPR-spin trapping and flow cytometric studies of free radicals generated using cold atmospheric argon plasma and X-ray irradiation in aqueous solutions and intracellular milieu. PLoS One 10: e0136956, 2015.

23. Tabuchi Y, Yunoki T, Hoshi N, Suzuki N and Kondo T: Genes and gene networks involved in sodium fluoride-elicited cell death accompanying endoplasmic reticulum stress in oral epithelial cells. Int J Mol Sci 15: 8959-8978, 2014.

24. Furusawa Y, Tabuchi Y, Wada S, Takasaki I, Ohtsuka K and Kondo T: Identification of biological functions and gene networks regulated by heat stress in U937 human lymphoma cells. Int J Mol Med 28: 143-151, 2011.

25. Kariya A, Tabuchi Y, Yunoki T and Kondo T: Identification of common gene networks responsive to mild hyperthermia in human cancer cells. Int J Mol Med 32: 195-202, 2013.

26. Kariya A, Furusawa Y, Yunoki T, Kondo T and Tabuchi Y: A microRNA-27a mimic sensitizes human oral squamous cell carcinoma HSC-4 cells to hyperthermia through downregulation of Hsp110 and Hsp90. Int J Mol Med 34: 334-340, 2014.

27. Finkel $\mathrm{T}$ and Holbrook NJ: Oxidants, oxidative stress and the biology of ageing. Nature 408: 239-247, 2000.

28. Li FJ, Kondo T, Zhao QL, Tanabe K, Ogawa R, Li M and Arai Y: Enhancement of hyperthermia-induced apoptosis by a free radical initiator, 2,2'-azobis (2-amidinopropane) dihydrochloride, in human histiocytic lymphoma U937 cells. Free Radic Res 35: 281-299, 2001

29. Honda H, Kondo T, Zhao QL, Feril LB Jr and Kitagawa H: Role of intracellular calcium ions and reactive oxygen species in apoptosis induced by ultrasound. Ultrasound Med Biol 30: 683-692, 2004

30. Li P, Zhao QL, Wu LH, Jawaid P, Jiao YF, Kadowaki M and Kondo T: Isofraxidin, a potent reactive oxygen species (ROS) scavenger, protects human leukemia cells from radiation-induced apoptosis via ROS/mitochondria pathway in $\mathrm{p} 53$-independent manner. Apoptosis 19: 1043-1053, 2014.

31. Dalli J, Jones CP, Cavalcanti DM, Farsky SH, Perretti M and Rankin SM: Annexin A1 regulates neutrophil clearance by macrophages in the mouse bone marrow. FASEB J 26: 387-396, 2012.

32. Hua B, Tamamori-Adachi M, Luo Y, Tamura K, Morioka M, Fukuda M, Tanaka Y and Kitajima S: A splice variant of stress response gene ATF3 counteracts NF-kappaB-dependent antiapoptosis through inhibiting recruitment of CREB-binding protein/p300 coactivator. J Biol Chem 281: 1620-1629, 2006

33. Zhang X, Zhang L, Yang H, Huang X, Otu H, Libermann TA, DeWolf WC, Khosravi-Far R and Olumi AF: c-Fos as a proapoptotic agent in TRAIL-induced apoptosis in prostate cancer cells. Cancer Res 67: 9425-9434, 2007.

34. Ruiter GA, Zerp SF, Bartelink H, van Blitterswijk WJ and Verheij M: Alkyl-lysophospholipids activate the SAPK/JNK pathway and enhance radiation-induced apoptosis. Cancer Res 59: 2457-2463, 1999. 
35. Li Z, Zhao J, Li Q, Yang W, Song Q, Li W and Liu J: KLF4 promotes hydrogen-peroxide-induced apoptosis of chronic myeloid leukemia cells involving the bcl-2/bax pathway. Cell Stress Chaperones 15: 905-912, 2010.

36. Newman JR and Keating AE: Comprehensive identification of human bZIP interactions with coiled-coil arrays. Science 300: 2097-2101, 2003

37. Mils V, Piette J, Barette C, Veyrune J, Tesnière A, Escot C, Guilhou JJ and Basset-Séguin N: The proto-oncogene c-fos increases the sensitivity of keratinocytes to apoptosis. Oncogene 14 1555-1561, 1997.

38. Marlowe JL and Puga A: Aryl hydrocarbon receptor, cell cycle regulation, toxicity, and tumorigenesis. J Cell Biochem 96 : 1174-1184, 2005.

39. Pham CG, Bubici C, Zazzeroni F, Papa S, Jones J, Alvarez K, Jayawardena S, De Smaele E, Cong R, Beaumont C, et al: Ferritin heavy chain upregulation by NF-kappaB inhibits TNFalphainduced apoptosis by suppressing reactive oxygen species. Cell 119: 529-542, 2004.

40. Wang J, Yang J, Zou Y, Huang GL and He ZW: Orphan nuclear receptor nurrl as a potential novel marker for progression in human prostate cancer. Asian Pac J Cancer Prev 14: 2023-2028, 2013.

41. Beere HM: 'The stress of dying': The role of heat shock proteins in the regulation of apoptosis. J Cell Sci 117: 2641-2651, 2004.

42. Kabbage M and Dickman MB: The BAG proteins: A ubiquitous family of chaperone regulators. Cell Mol Life Sci 65: 1390-1402, 2008.

43. Evert BO, Wüllner U and Klockgether T: Cell death in polyglutamine diseases. Cell Tissue Res 301: 189-204, 2000.

44. Bindu S, Pal C, Dey S, Goyal M, Alam A, Iqbal MS, Dutta S, Sarkar S, Kumar R, Maity P and Bandyopadhyay U: Translocation of heme oxygenase-1 to mitochondria is a novel cytoprotective mechanism against non-steroidal anti-inflammatory drug-induced mitochondrial oxidative stress, apoptosis, and gastric mucosal injury. J Biol Chem 286: 39387-39402, 2011.
45. Yang Z, Zhuang L, Szatmary P, Wen L, Sun H, Lu Y, Xu Q and Chen X: Upregulation of heat shock proteins (HSPA12A, HSP90B1, HSPA4, HSPA5 and HSPA6) in tumour tissues is associated with poor outcomes from HBV-related early-stage hepatocellular carcinoma. Int J Med Sci 12: 256-263, 2015.

46. Yunoki T, Tabuchi Y, Hayashi A and Kondo T: BAG3 protects against hyperthermic stress by modulating NF- $\kappa \mathrm{B}$ and ERK activities in human retinoblastoma cells. Graefes Arch Clin Exp Ophthalmol 253: 399-407, 2015.

47. Tanabe M, Nakai A, Kawazoe Y and Nagata K: Different thresholds in the responses of two heat shock transcription factors, HSF1 and HSF3. J Biol Chem 272: 15389-15395, 1997.

48. Ahn SG and Thiele DJ: Redox regulation of mammalian heat shock factor 1 is essential for Hsp gene activation and protection from stress. Genes Dev 17: 516-528, 2003.

49. Liebmann J, Scherer J, Bibinov N, Rajasekaran P, Kovacs R, Gesche R, Awakowicz P and Kolb-Bachofen V: Biological effects of nitric oxide generated by an atmospheric pressure gas-plasma on human skin cells. Nitric Oxide 24: 8-16, 2011.

50. Byrne CR and Hanson PJ: Induction of heat shock protein 72 by a nitric oxide donor in guinea-pig gastric mucosal cells. Eur J Pharmacol 353: 117-122, 1998.

51. Manucha W and Vallés PG: Cytoprotective role of nitric oxide associated with Hsp70 expression in neonatal obstructive nephropathy. Nitric Oxide 18: 204-215, 2008.

52. Manucha W and Vallés P: Hsp70/nitric oxide relationship in apoptotic modulation during obstructive nephropathy. Cell Stress Chaperones 13: 413-420, 2008. 